DOI: $10.17957 / \mathrm{IJAB} / 15.1762$

http://www.fspublishers.org

\title{
Production of Antifungal Gelatinase by Enterococcus durans S2C and its Potential Role in the Biological Control
}

\author{
Zafar Hayat ${ }^{1}$, Irum Mukhtar ${ }^{2}$, Faluk Shair ${ }^{1}$, Kifayat Ullah ${ }^{1}$, Ahmed Hafeez ${ }^{1}$, Fauzia Yusuf Hafeez ${ }^{1}$ and Anwar Ullah ${ }^{1 *}$ \\ ${ }^{1}$ Department of Biosciences, COMSATS University Islamabad, Pakistan \\ ${ }^{2}$ Institute of Oceanography Minjiang University, Fuzhou, China \\ *For correspondence: anwar.ms90@yahoo.com; anwarullah@comsats.edu.pk \\ Received 18 November 2020; Accepted 26 February 2021; Published 16 April 2021
}

\begin{abstract}
Probiotic bacteria are good sources for antimicrobial and are normal microbiota of the gastrointestinal tract of animals and humans. Enterococci are found everywhere in nature and have been utilized as probiotics in the food industry. In the present study, Enterococcus durans S2C strain was isolated from raw cow's milk using the culture-dependent method and evaluated for antifungal properties. The strain S2C showed promising extracellular proteolytic activity and the extracellular peptide was an important source of antifungal activity. Besides, a low rate of antibiotic resistance and non-hemolytic activity was detected in $E$. durans $\mathrm{S} 2 \mathrm{C}$. Strong antifungal activity of E. durans against two plant pathogenic fungi namely Fusarium oxysporum and Rhizoctonia solani was also recorded. Antifungal activity evaluation showed that $R$. solani colony was the most inhibited fungus followed by $F$. oxysporum. Gelatinase enzyme having antifungal activity was also purified from E. durans S2C isolate. This study concludes that the environmental-derived E. durans S2C strain can be selected for technological application to control pathogenic fungi and to protect the economic value of the crops. (C) 2021 Friends Science Publishers
\end{abstract}

Keywords: Antifungal activity; Antibiotic resistance pattern; Enterococcus durans; Gelatinase; Raw milk

\section{Introduction}

Serious economic losses are incurred annually because of disease-causing microbial agents. Among these microbial agents, fungal plant pathogens are the most important ones (Almeida et al. 2019). The genus Fusarium alone has been known to infect over 100 host organisms. This has resulted in significant losses of a wide variety of crops including cotton, banana, tomato, onion, and melon (Michielse and Rep 2009; Jamal et al. 2015; Akhtar and Javaid 2018). Fusarium oxysporum invades host plants through their roots or stems and propagates within their vascular system. This leads to wilting and eventually death of the plant. This becomes a serious issue because of its persistence in the soil, which makes it difficult to eradicate (Sun et al. 2017. Similarly, Rhizoctonia solani has been reported to affect a wide range of hosts such as grasses, potatoes, and sugar beets. Its infection results in seed and fruit decay, foliage diseases, damping-off, and stem cankers (Xia et al. 2017). An issue of using chemicals to control these infections is that the substances tend to bio-accumulate in the plants and then move up the food chain, which can have disastrous consequences (Özkara et al. 2016). Along with this issue, the rising in fungal resistance against the most common chemical agents and a push in the market for more fungicidefree fruits and vegetables have begun driving researchers to look for alternative solutions for fungal control. The desire, which has seen substantial growth in the past decades, prompted a search for microbial products to control plant maladies. Use of biocontrol to inhibit the growth of pathogenic microorganisms has long been considered a potential alternative to chemical fungicides (CarmonaHernandez et al. 2019; Ali et al. 2020; Sharf et al. 2021).

Lactic acid bacteria (LAB) are known to produce lactic acid as a major product by the carbohydrate metabolism of food. Other properties of this group include a Gram-positive nature, catalase-negative, immobility, and lack of spore formation. They have generally been recognized as safe status (Fhoula et al. 2013). Thriving in carbohydrate-rich environments, they are commonly found in milk and meat along with plants, animals, and the intestinal mucosa of humans (Bintsis 2018). They are particularly prolific in various fermented foods (Tamang et al. 2020). Owing to their ability to prevent the growth of entero-pathogenic bacteria and promote health, they have seen use as probiotics. LABs have found many industrial applications owing to their distinctive properties, such as their ability to produce organic acids, exopolysaccharides, aromatic and antimicrobial compounds. Numerous researchers have reported the ability of certain LAB strains to suppress food-borne pathogens like Escherichia coli and Salmonella typhimurium (Darsanaki et al. 2012), as well as

To cite this paper: Hayat Z, I Mukhtar, F Shair, K Ullah, A Hafeez, FY Hafeez, A Ullah (2021). Production of antifungal gelatinase by Enterococcus durans S2C and its potential role in the biological control. Intl J Agric Biol 25:1043-1050 
phytopathogenic bacteria such as Erwinia carotovora and fungi including Aspergillus flavus, F. graminarum, and Penicillium expansum (Daranas et al. 2019).

The genus Enterococcus is a member of LAB and widespread in nature. They are part of the gastrointestinal flora and are detected in samples from all over the animal kingdom, insects, lower vertebrates, and humans (David et al. 2012; David and Onifade 2018). They produce small, extracellular metabolites that have been reported against food-borne pathogens and, more recently, against plant pathogens (Belguesmia et al. 2013). In this study, we evaluated the anti-fungal ability of an Enterococcus species. Some additional properties of this species regarding safety aspects were also investigated in this study.

\section{Materials and Methods}

\section{Isolation of bacterial and fungal species}

Eight raw milk samples were randomly obtained from apparently healthy cows owned by locals from different localities in Islamabad, Pakistan. The milk samples were collected in sterile $50 \mathrm{~mL}$ tubes stored in an icebox and transferred to the lab within $24 \mathrm{~h}$. From raw milk samples, the lactic acid bacteria (LAB) were isolated on de Man, Rogosa, and Sharpe (MRS) agar using the spread-plate method. Inoculated plates were incubated at $37^{\circ} \mathrm{C}$ for $48 \mathrm{~h}$. After incubation, the bacterial colonies were purified to investigate for LAB characteristics (Gram-positive, catalase-negative, and oxidase-negative). Isolates with Gram-positive and catalase-negative characters were considered for further identification.

For the antifungal assay, two plant pathogen isolates i.e., $F$. oxysporum and $R$. solani were collected from Applied Microbiology and Biotechnology lab, COMSATS University Islamabad Pakistan, and maintained on 2\% Potato Dextrose Agar (PDA) for further use.

\section{Molecular characterization and selection of bacterial isolates}

Genomic DNA was extracted from fifteen LAB isolates using phenol/chloroform method with some modifications (Cheng and Jiang 2006). The 16S rRNA gene was amplified using primers P1 "CGGGATCCAGAGTTTGATCCTGGTCAGAACGAAC GCT" and P6 "CGGGATCCTACGGCTACCTTGTTACGACTTCACC

CC" (Tan et al. 1997). An aliquot of $25 \mu \mathrm{L}$ reaction mixture consisting of $1.5 \mathrm{~m} M \mathrm{MgCl}_{2}$, 1X Taq buffer, $10 \mathrm{~m} M$ dNTPS, 1-1.5 U Taq DNA polymerase and $10 \mu \mathrm{M}$ primer was subjected to amplification (Applied Biosystems). The cycling conditions for PCR were as follows: initial denaturation at $94^{\circ} \mathrm{C}$ for $4 \mathrm{~min} ; 30$ cycles of denaturation at $94^{\circ} \mathrm{C}$ for $30 \mathrm{~s}$, annealing at $55^{\circ} \mathrm{C}$ for $30 \mathrm{~s}$, and extension at $72^{\circ} \mathrm{C}$ for $1 \mathrm{~min}$, and final extension at $72^{\circ} \mathrm{C}$ for $4 \mathrm{~min}$. Amplified product were sent for sequencing.
Obtained sequences were aligned using chromas software version 2.6.6 with default parameters and BLAST searched to find their pairwise identities on NCBI database. Similar sequences were aligned using Clustal W and phylogenetic tree was constructed using the neighborjoining method in Mega software. On the basis of molecular identification, only two isolates were identified as Enterococcus durans. Due 16S rRNA gene similarity, only E. durans $\mathrm{S} 2 \mathrm{C}$ was used in further biochemical tests and pathogenicity assay. The fresh culture was maintained in Tryptic Soy Broth (TSB), at $37^{\circ} \mathrm{C}$ for $24 \mathrm{~h}$ and stored at $-80^{\circ} \mathrm{C}$ as frozen stock culture in TSB containing $20 \%$ (v/v) glycerol.

\section{Biochemical characteristics of the enterococci}

Detection of bio-film formation: To assess Enterococci virulence, biofilm formation test was also conducted using tube method (Deka 2014). A loopful inoculum of E. durans S2C was taken from overnight grown culture in nutrient agar and was inoculated into $10 \mathrm{~mL}$ of TSB broth containing $1 \%$ glucose. After incubation at $37^{\circ} \mathrm{C}$ for 24 $\mathrm{h}$, the cultures were decanted, and tubes were washed with Phosphate buffer saline (at $\mathrm{pH}$ of 7.3) followed by drying and stained with $0.1 \%$ crystal violet. The deionized water was used to wash out the excess stain and the tubes were dried in an inverted position to observe bio-film formation. Results were considered positive if a visible film lined produced in the base and wall of the tube. The experiment was performed in triplicate and repeated three times.

\section{Hemolytic and gelatinase hydrolysis test}

To understand the virulence potential of dairy enterococci, E. durans S2C strain was also tested for hemolytic and gelatinase activities. For hemolytic activity, commercial blood agar plates were inoculated with fresh culture of S2C strain and incubated at $37^{\circ} \mathrm{C}$ under anaerobic conditions (Valenzuela et al. 2009). Hemolytic reaction was recorded after $24-48 \mathrm{~h}$ and the test was conducted in triplicate.

The gelatinase activity of the $E$. durans $\mathrm{S} 2 \mathrm{C}$ strain was evaluated by tube method. A $12 \mathrm{~h}$ pure culture of cells was inoculated into tubes containing $5 \mathrm{~mL}$ of growth medium [0.5\% Bacto Peptone, $0.25 \%$ yeast extract, $0.5 \%$ glucose, $0.1 \% \mathrm{MgSO}_{4} .7 \mathrm{H}_{2} \mathrm{O}$, and $0.02 \mathrm{M}$ phosphate buffer with $12 \%$ gelatin $(\mathrm{pH} 7)]$. Gelatinase activity was discovered as medium liquefaction at room temperature for 1 week of incubation.

\section{Assessment of antibiotic susceptibility of $E$. durans}

Disk diffusion method according to Clinical Laboratory Standards Institute guidelines (CLSI, 2017), was used to determine antibiotic resistance in E. durans $\mathrm{S} 2 \mathrm{C}$ and the 
following eight antibiotic discs (Oxoid) were tested: choloromphenicol $\left(30 \mu \mathrm{g} \mathrm{disc}^{-1}\right)$, tetracycline $(30 \mu \mathrm{g} / \mathrm{disc})$, vancomycin $\left(30 \mu \mathrm{g} \mathrm{disc} c^{-1}\right)$, streptomycin $\left(10 \mu \mathrm{g} \mathrm{disc}^{-1}\right)$, piperacillin (100 $\left.\mu \mathrm{g} \mathrm{disc} \mathrm{d}^{-1}\right)$, levofloxacin $(5 \mu \mathrm{g} / \mathrm{disc})$, minocycline $(30 \mu \mathrm{g} / \mathrm{disc})$ and amoxicillin $\left(10 \mu \mathrm{g} \mathrm{disc}{ }^{-1}\right)$. Based on the measured inhibition zones, the strains were categorized as susceptible, intermediate, or resistant according to the criteria of the CLSI.

\section{Antifungal assay}

A mycelial disc $(5 \mathrm{~mm})$ from 3 days old fungal culture was placed in the center of $2 \%$ PDA plates. The bacterium inoculum was sown with a sterile stick at a distance of 2.5 $\mathrm{cm}$ from the fungal disc and inoculated plates were kept in darkness for 7 days at $25^{\circ} \mathrm{C}$. The inhibition of fungal growth was quantified by measuring the colony diameter and calculating percentage inhibition using the following formula:

Percentage inhibition $=(C-T) \times 100 / C$

Where, $\mathrm{C}=$ colony diameter $(\mathrm{mm})$ of the control and

$\mathrm{T}=$ colony diameter $(\mathrm{mm})$ of the test plate.

Partial purification of proteins involved in biofilm formation

Partial purification of proteins was performed by method as described by Chiba et al. (2015). To produce biofilms, single colonies grown on TSA plates were picked and inoculated in $3 \mathrm{~mL}$ of TSB. They were placed overnight in a shaking incubator at $37^{\circ} \mathrm{C}$. 1000 fold dilution was then carried out in $10 \mathrm{~mL}$ of TSB medium, followed by static incubation at $37^{\circ} \mathrm{C}$ for $24 \mathrm{~h}$. After incubation, TSB with bacterial culture was centrifuged at $25^{\circ} \mathrm{C}$ for $10 \mathrm{~min}$ at $8000 \mathrm{rpm}$. To extract the ECM (Extracellular Matrix) components, the supernatant was discarded, while the pellet was resuspended. Centrifugation was again carried out this time at $5000 \mathrm{rpm}$ and the supernatant obtained was transferred to another clean tube. These partially purified extracellular proteins were used to assess protease and gelatinase activities and characterization in separate assays.

\section{Protease activity from partially purified extracellular proteins}

Protease activity was screened by agar well diffusion assay (Vijayaraghavan and Vincent 2013). Autoclaved, sterile skim milk was added to LB agar medium at $37^{\circ} \mathrm{C}$ with a $\mathrm{pH}$ of 6.5 , and then poured into a Petri plate. Thirty $\mu \mathrm{L}$ of the extracted ECM was added to the well of the plate. Formation of a clear zone around the well as a result of skim milk hydrolysis indicated that the sample was protease positive.

\section{Molecular size approximation SDS-PAGE analysis for} protease

Molecular weight of protease in ECM was estimated by SDS-PAGE with some modifications (Fitriani and Guven 2018). The 4\% stacking gel (pH 6.8) and 15\% separating gel ( $\mathrm{pH} 8.8$ ) was utilized. The Running buffer consisted of $0.1 \%(\mathrm{w} / \mathrm{v})$ SDS (pH 8.35), $192 \mathrm{~m} M$ glycine and $25 \mathrm{mM}$ Tris. $4 \mu \mathrm{L}$ of (Thermo Scientific Pre-stained Protein Ladder) was used as a standard. Voltage of $150 \mathrm{~V}$ was applied for 2 $\mathrm{h}$ and staining was carried out in a solution with $50 \%$

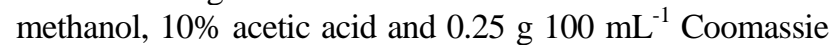
Brilliant Blue. De-staining was done in a $50 \%$ methanol, $50 \%$ distilled water solution.

\section{Purification of gelatinase using ammonium sulphate precipitation and membrane filters}

Precipitation of protein using ammonium sulphate was carried out using $10 \mathrm{~mL}$ of protein extract. After adding the ammonium sulphate, solution was stirred to reach some degree of saturation and then placed on ice for around 30 min. Centrifugation was then carried out at $4^{\circ} \mathrm{C}$ for $15 \mathrm{~min}$ at $13000 \mathrm{rpm}$. The obtained pellet was suspended in $1 \mathrm{~mL}$ PBS buffer at $\mathrm{pH} 7$. The above procedure was carried out multiple times to obtain 20, 30, 40, 50, 60, 70 and $80 \%$ saturation. Further purification was then done by application of molecular weight cut size membrane filters. Aliquots were then again analyzed on SDS-PAGE.

\section{Determination of molecular weight of protein with SDS PAGE}

After running gel, the relative migration distance $(R F)$ was determined of the standards of protein and the unknown protein. The migration distance can be determined using the following equation:

$R F=$ Migration distance of the protein/Migration distance of the dye front

\section{Gelatinase activity assay}

The phenotypic assay of gelatinase activity performed through the gelatin liquefaction method (Cruz and Torres 2012). Purified protein $(30 \mu \mathrm{L})$ was added in a falcon tube containing Gelatin medium (nutrient gelatin) with the following formulation per litter: peptone $5 \mathrm{~g}$, beef extract $3 \mathrm{~g}$, gelatin $120 \mathrm{~g}, \mathrm{pH} 7$. After placing the tube overnight at $4^{\circ} \mathrm{C}$, tube was observed for liquefaction. The test was considered gelatinase positive if the gelatin liquefied.

\section{Antifungal activity of purified gelatinase}

Purified gelatinase was tested for inhibitory activity against spore germination of $F$. oxysporum and $R$. solani. The antifungal activity of gelatinase was estimated using a 
growth inhibition assay described earlier (Zandvakili et al. 2017). Purified gelatinase $(100 \mu \mathrm{L})$ was mixed with the spores of each pathogenic species in the broth separately and was spread on 2\% PDA agar plates. The test microorganism's spore's broth without gelatinase served as control group. After 4 days of incubation at $25^{\circ} \mathrm{C}$, the fungal colonies were checked for spore germination. The inhibition percentage of gelatinase activity was measured by formula described below:

Inhibition ratio $(\%)=(\mathrm{C}-\mathrm{E}) / \mathrm{C} \times 100 \%$

Where $C$ is the average diameter of colonies in the control, $E$ is the average diameter of colonies in the experimental group. All experiments were conducted in triplicate.

\section{Results}

\section{Molecular identification and biochemical characteristics of enterococci isolate}

In this work, 35 bacterial isolates were randomly selected from eight collected milk samples. They were all Gram-positive bacteria without catalase activity. Obtained sequences of isolates were identified by pairwise numerical comparison with an extensive existing database (Ez Taxon) comprising multiple well characterized reference strains of all validly described bacterial species. On the basis of $16 \mathrm{~S}$ sequencing, only two bacterial isolates were identified as Enterococci durans without catalase activity (Fig. 1; Fig. 2). The sequence of $E$. durans S2C has been submitted to Gene bank under accession number (MG877665) and its closest homologue is shown in Table 1. The E. durans S2C was capable to grow at $45^{\circ} \mathrm{C}$, protease positive and also showed positive indication for biofilm formation.

\section{Biochemical tests and antibiotic susceptibility of bacterial isolate}

In the present study, E. durans S2C presented moderate capability of biofilm formation on abiotic surfaces; while, exhibited multiple antibiotic sensitivity against antibiotics i.e. choloromphenicol, streptomycin, tetracycline, piperacillin, vancomycin, levofloxacin, minocycline, amoxicillin as shown in Table 2. Hemolytic test was also negative for this bacterial isolate; however, liquefaction of the growth medium inoculated with $E$. durans S2C, indicates gelatinase activity in the medium, one of the virulence factors of Enterococcus.

\section{Antagonist effect of $E$. durans against phytopathogens}

In the dual-culture plate test, the bacterial isolate $\mathrm{S} 2 \mathrm{C}$ showed antagonistic activity against the mycelia growth of $F$. oxysporum and $R$. solai after four days' incubation (Fig. 3 ), and the inhibition rates were 50 and $52.6 \%$, respectively as shown in Table 3.

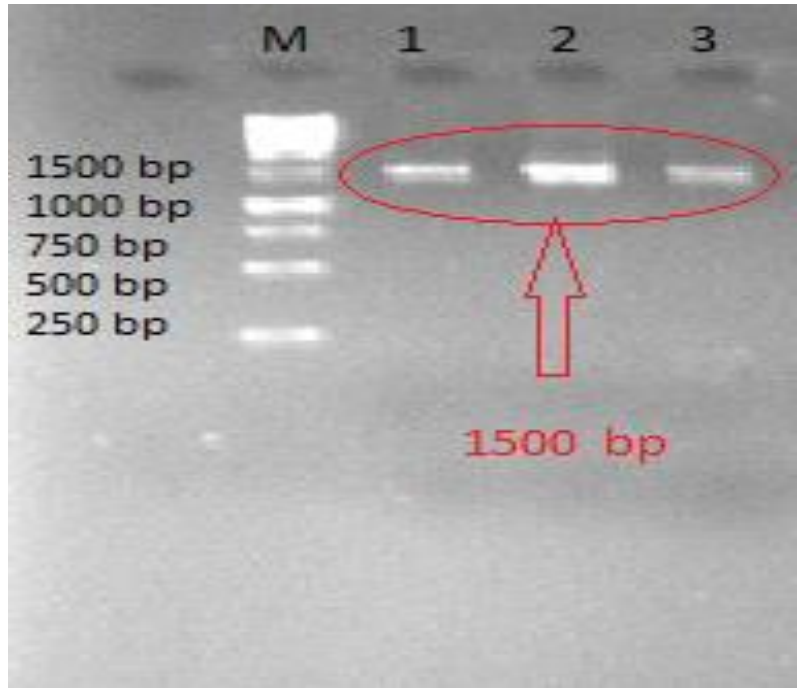

Fig. 1: PCR Amplification of 16S rRNA gene: Lane (1-3) showing replicate of $16 \mathrm{~S}$ rRNA gene, lane $M$ showing DNA markar of $1 \mathrm{~kb}$

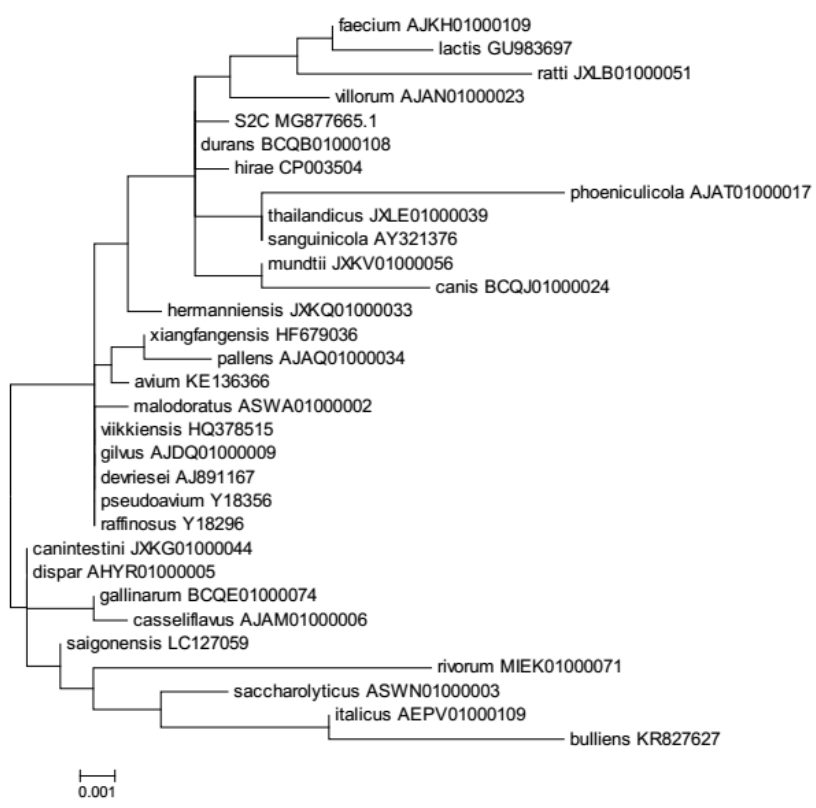

Fig. 2: Phylogenetic tree analysis on the basis of $16 \mathrm{~S}$ rRNA gene

\section{Purification and characterization of gelatinase}

The proteins were partially purified and analyzed by SDS-PAGE. The partially purified proteins were protease positive. The gelatinase enzyme was purified from partially purified proteins by combination of ammonium sulfate precipitation method and molecular cut size membrane filters. The molecular weight of 37.9 $\mathrm{kDa}$ gelatinase was estimated (Fig. 4). Gelatin liquefaction test was positive as the tube containing purified gelatinase was liquefied while that of the control has remained solid. 
Table 1: Identification of bacterial S2C isolate on the basis of 16S rRNA

\begin{tabular}{|c|c|c|c|c|c|}
\hline Strain Name & Source & Closest strain & Percentage similarity & Accession number & Database \\
\hline Enterococcus spp. S2C & Milk & Enterococcus sp. strain CAU7950 & $100 \%$ & MG877665 & NCBI \\
\hline Enterococcus spp. S2C & Milk & E. durans NBRC 100479(T) & $99.90 \%$ & MG877665 & Ez-Taxon \\
\hline
\end{tabular}

Table 2: Antibiotics resistance patterns of bacterial S2C isolate

\begin{tabular}{|c|c|c|c|c|}
\hline Antibiotic Name & Disk content $(\mu \mathrm{g})$ & Zone diameter (mm) & Mean (mm) & Resistant/intermediate/sensitive \\
\hline Choloromphenicol & 30 & $25,24,24$ & 24.33 & $\mathrm{~S}$ \\
\hline Streptomycin & 10 & $19,19,18$ & 18.66 & $\mathrm{~S}$ \\
\hline Tetracycline & 30 & $19,20,20$ & 19.66 & $\mathrm{~S}$ \\
\hline Vancomycin & 30 & $22,20,21$ & 21 & $\mathrm{~S}$ \\
\hline Levofloxacin & 5 & $32,33,34$ & 33 & $\mathrm{~S}$ \\
\hline Minocycline & 30 & $36,37,35.6$ & 36.2 & $\mathrm{~S}$ \\
\hline Amoxicillin & 10 & $22,21,22$ & 21.66 & $\mathrm{~S}$ \\
\hline
\end{tabular}

S indicate "sensitive"

Table 3: Antifungal activity of bacterial S2C isolate and purified enzyme against phytopathogens

\begin{tabular}{|c|c|c|c|c|}
\hline Fungal Pathogen & $\begin{array}{l}\text { Control colony diameter } \\
(\mathrm{mm})\end{array}$ & $\begin{array}{l}\text { Experimental colony diameter } \\
(\mathrm{mm})\end{array}$ & Percent inhibition & $\begin{array}{l}\text { Fungal spores production } / 100 \mu \mathrm{L} \\
\text { in the presences of purified enzyme }\end{array}$ \\
\hline Rhizoctonia solani & 19 & 10 & 52.6 & 12 \\
\hline Fusarium oxysporum & 20 & 10 & 50 & 9 \\
\hline
\end{tabular}
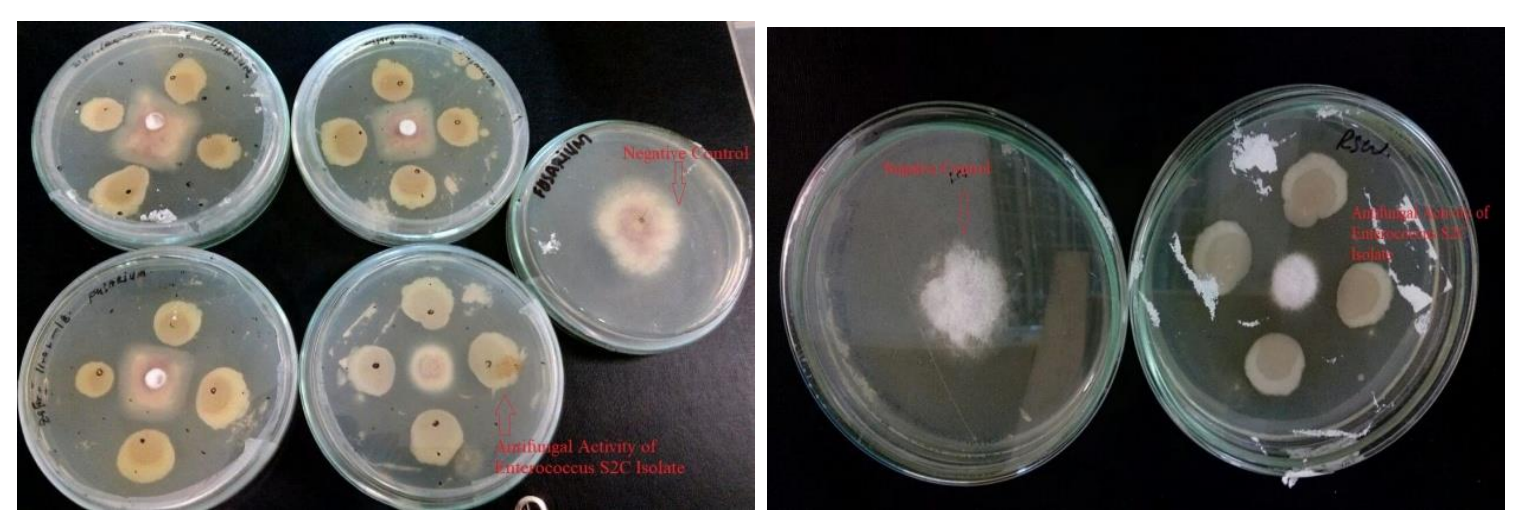

Fig. 3: Antifungal activity of Enterococcus S2C against Fusarium oxysporum (A) and Rhizoctonia solani (B)

\section{Antifungal activity of purified gelatinase}

Result showed that $100 \mu \mathrm{L}$ of purified gelatinase significantly inhibited the conidial growth of $R$. solonai and $F$. oxysporum as shown in Table 3 . It also indicates that $E$. durans possess remarkable antifungal activity toward tested fungi compared to control.

\section{Discussion}

Enterococcus spp. known for their diversity, found everywhere in nature, are present in fermented foods. The research interests are increasing in enterococci as probiotic candidates (Hussein et al. 2020). LAB strains were isolated from various sources which inhibited the growth of $F$. oxysporum and they were belonged to the members of various LAB genera like Lactococcus, Lactobacillus,
Enterococcus and Pediococcus (Varsha et al. 2014). In this study, Enterococcus species was isolated with the idea of using the bacterial isolate as bio-control agent against phytopathogens. The isolated strain S2C showed the antifungal activity against $F$. oxysporum and $R$. solonai.

The existence of enterococci in food products as a natural flora has led to a lot of controversy over the safety aspects for their use, as scientists have found a few confirmations about the association of these microorganisms with clinical infections (Bondi et al. 2020). Enterococci food strains have also been found to contain antibiotic resistance genes normally found in conjugative plasmids, increasing the risk of genetic transmission. Despite these considerations, the enterococci present in many cheeses at high densities and are supposed to play a helpful part in the development of flavors (Hanchi et al. 2018; Garcia-Solache and Rice 2019). Verification of virulence factors was 


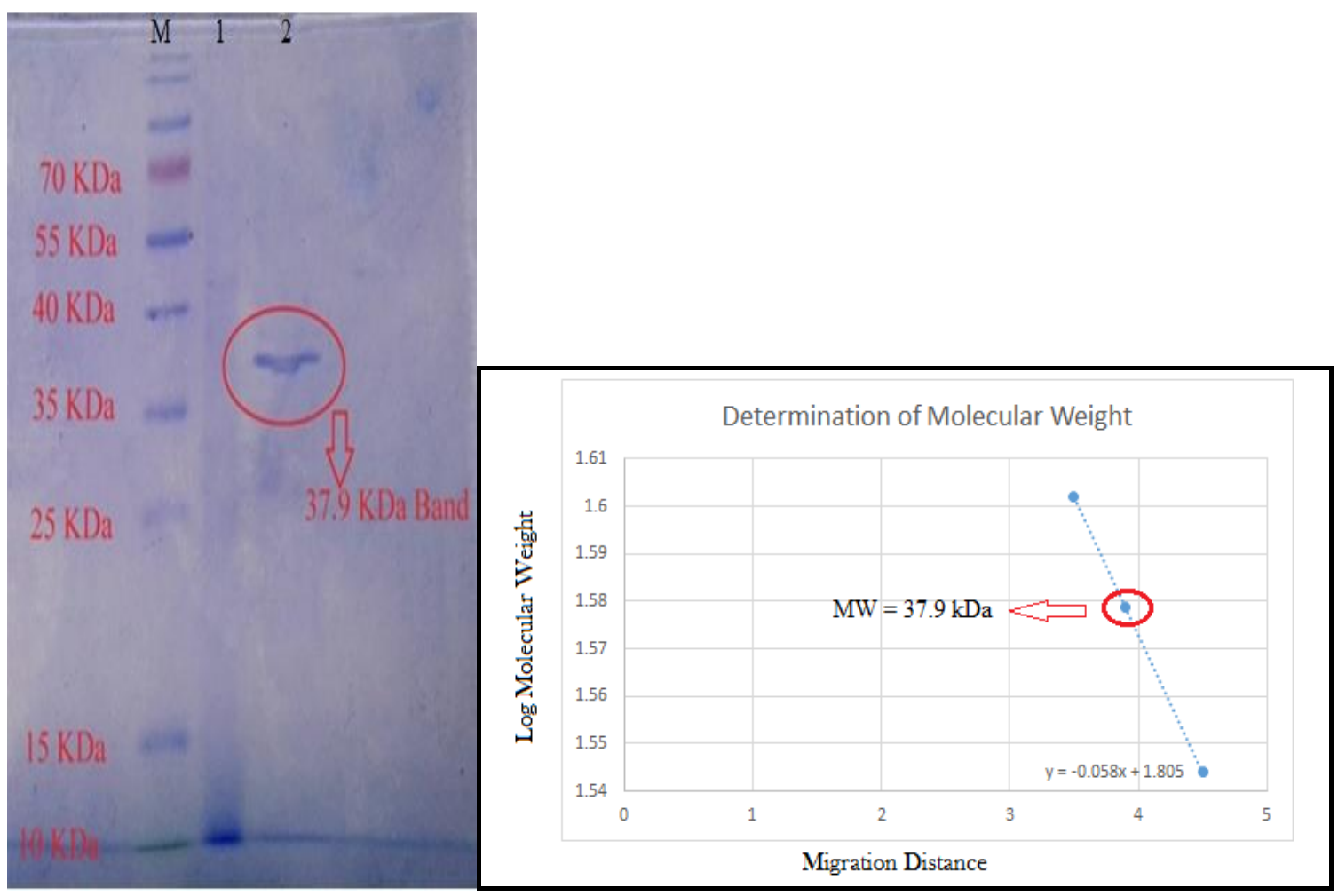

Fig. 4: (A) SDS PAGE analysis of purified enzyme: Lane M shows Protein Markar, Lane 2 shows purified enzyme of 37.9 kDa (B) Molecular weight estimation of purified enzyme

therefore of utmost importance among enterococci through phenotypic methodologies. Biofilm formation, hemolytic and gelatinase activities by enterococci have been recently recognized as a factor that contributes for pathogenicity. In the present study, stain S2C isolates presented moderate ability to form biofilm on abiotic surfaces and gelatinase activity. A positive correlation among gelatinase production and formation of biofilm was observed in present study. However, Mohamed and Murray (2005) found no association between gelatinase production and biofilm formation in enterococci of clinical isolates. The development of resistance to high levels of glycopeptides like vancomycin is a major concern for enterococci (Zalipour et al. 2019). Enterococcus species examined in this study, however, was found to be sensitive to vancomycin and other clinically significant antibiotics (carbenicillin, penicillin, chloramphenicol and amoxicillin/clavulanic acid), therefore can be considered as biocontrol agent.

E. faecalis present in filled root canals produced gelatinase as one of the virulence factors that may be linked with their survival. E. faecalis in large proportion are isolated from hospitalized patients that can express gelatinases (Guneser and Eldeniz 2016). Under the consideration from an endodontic point, the expression of gelatinase has been reported to be higher in biofilm-positive strains (Wang et al. 2011). The genes related to virulence factors are sporadically present in enterococci isolates which are tested in dairy products, so that are not associated with cytotoxic activity, suggesting that adhesion and biofilm formation are more associated with gut colonization (Popović et al. 2018). In the present study, gelatinase was also isolated from the Enterococcus species S2C from raw milk source and the purified gelatinase showed antifungal activity against phytopathogens.

\section{Conclusion}

Raw milk associated E. durans $\mathrm{S} 2 \mathrm{C}$ is considered to be safe and has good potential to control fungal pathogens in agriculture sector. The results produced in this study encourage us to carry out other tests to evaluate the probiotic potential of this strain and also investigate the deep characterization of the gelatinase enzyme produced.

\section{Acknowledgements}

The authors would like to thank COMSATS University Islamabad, Pakistan for providing research facilities and funding the research. They would like to extend their thanks to the colleagues who voluntarily participated in the study. 


\section{Author Contributions}

AU gives the idea of presented study and supervised the research work. ZH planned and conducted the research work. FS planned and conducted antifungal assay. IM, KU, $\mathrm{AH}$ and FYH helped in preparing manuscript and finalized the manuscript by giving feedback.

\section{Conflicts of Interest}

The authors declare no conflict of interest.

\section{Data Availability}

The data will be available upon reasonable requests to the corresponding author.

\section{Ethics approval}

Not applicable.

\section{References}

Akhtar R, A Javaid (2018). Biological management of basal rot of onion by Trichoderma harzianum and Withania somnifera. Plant Danin 36; Article e 018170507

Ali A, A Javaid, A Shoaib, IH Khan (2020). Effect of soil amendment with Chenopodium album dry biomass and two Trichoderma species on growth of chickpea var. Noor 2009 in Sclerotium rolfsii contaminated soil. Egypt J Biol Pest Cont 30; Article 102

AlmeidaF,MLRodrigues, C Coelho (2019). The still underestimated problem of fungal diseases worldwide. Front Microbiol 10; Article 214

Belguesmia Y, Y Choiset, H Rabesona, M Baudy-Floc'h, G Le Blay, T Haertlé, JM Chobert (2013). Antifungal properties of durancins isolated from Enterococcus durans 5-11 and of its synthetic fragments. Lett Appl Microbiol 56:237-244

Bintsis T (2018). Lactic acid bacteria: Their applications in foods. $J$ Bacteriol Mycol Open Access 6:89-94

Bondi M, A Laukova, SD Niederhausern, P Messi, C Papadopoulou, V Economou (2020). Controversial aspects displayed by enterococci: Probiotics or pathogens? BioMed Res Intl 2020; Article 9816185

Carmona-Hernandez S, JJ Reyes-Pérez, RG Chiquito-Contreras, G RinconEnriquez, CR Cerdan-Cabrera, LG Hernandez-Montiel (2019). Biocontrol of postharvest fruit fungal diseases by bacterial antagonists: A review. Agronomy 9; Article 121

Cheng HR, N Jiang (2006). Extremely rapid extraction of DNA from bacteria and yeasts. Biotechnol Lett 28:55-59

Chiba A, S Sugimoto, F Sato, S Hori, Y Mizunoe (2015). A refined technique for extraction of extracellular matrices from bacterial biofilms and its applicability. Microb Biotechnol 8:392-403

CLSI (Clinical Laboratory Standards Institute) (2017). Performance Standards for Antimicrobial Susceptibility Testing. $27^{\text {th }}$ Ed. CLSI Supplement M100. Wayne, Pennsylvania, USA

Cruz TE, JM Torres (2012). Gelatin hydrolysis test protocol. In: Microbial LibraryAmerican Society for Microbiology,pp:1-10. Washington, USA

Daranas N, G Rosello, J Cabrefiga, I Donati, J Frances, E Badosa, F Spinelli, E Montesinos, A Bonaterra (2019). B iological control of bacterial plant diseases with Lactobacillus plantarum strains selected for their broad-spectrum activity. Ann Appl Biol 174:92-105

Darsanaki RK, ML Rokhi, MA Aliabadi (2012). Issazadeh K. Antimicrobial activities of Lactobacillus strains isolated from fresh vegetables. Middle East J Sci Res 11:1216-1219

David OM, OE Onifade (2018). Effects of partially purified enterocins from Enterococcus faecalis strains on the growth of some phytopathogenic fungi. Ruhuna J Sci 9:160-168
David OM, AO Oluduro, O Famurewa (2012). Property and antibacterial spectrum of partially purified enterocin produced by entrocinogenic Enterococcus faecalis isolated from the gut of cockroach. $A U J$ Technol 16:74-80

Deka N (2014). Comparison of tissue culture plate method, tube method and Congo red agar method for the detection of biofilm formation by Coagulase negative Staphylococcus isolated from non-clinical isolates. Intl J Curr Microbiol Appl Sci 3:810-815

Fhoula I, A Najjari, Y Turki, S Jaballah, A Boudabous, H Ouzari (2013). Diversity and antimicrobial properties of lactic acid bacteria isolated from rhizosphere of olive trees and desert truffles of Tunisia. BioMed Res Intl 2013; Article 405708

Fitriani S, K Guven (2018). Isolation, screening, partial purification and characterization of protease from halophilic bacteria isolated from Indonesian fermented food. Anadolu Üniv Bilim Teknol Derg-C Yaşam Biliml Biyoteknol 7:130-142

Garcia-Solache M, LB Rice (2019). The Enterococcus: A model of adaptability to its environment. Clin Microbiol Rev 32; Article e00058-18

Guneser MB, AU Eldeniz (2016). The effect of gelatinase production of Enterococcus faecalis on adhesion to dentin after irrigation with various endodontic irrigants. Acta Biomater Odontol Scand 2:144-149

Hanchi H, W Mottawea, K Sebei, R Hammami (2018). The genus Enterococcus: Between probiotic potential and safety concerns-an update. Front Micrbiol 9; Article 1971

Hussein WE, AG Abdlhamid, D Rocha-Mendoza, I Garcia-Cano, AE Yousef (2020). Assessment of safety and probiotic traits of Enterococcus durans OSY-EGY, isolated from Egyptian artisanal cheese, using comparative genomics and phenotypic analyses. Front Microbiol 11; Article 608314

Jamal Q, YS Lee, HD Jeon, YS Park, KY Kim (2015). Isolation and biocontrol potential of Bacillus amyloliquefaciens Y1 against fungal plant pathogens. Kor J Soil Sci Fert 48:485-491

Michielse CB, M Rep (2009). Pathogen profile update: Fusarium oxysporum. Mol Plant Pathol 10:311-324

Mohamed JA, BE Murray (2005). Lack of correlation of gelatinase production and biofilm formation in a large collection of Enterococcus faecalis isolates. J Clin Microbiol 43:5405-5407

Özkara A, D Akyıl, M Konuk (2016). Pesticides, environmental pollution, and health. Intech Open 10:Article 5772

Popović N, M Dinić, M Tolinački, S Mihajlović, A Terzić-Vidojević, S Bojić, J Djokic, N Golic, K Veljovic (2018). New insight into biofilm formation ability, the presence of virulence genes and probiotic potential of Enterococcus spp. dairy isolates. Front Microbiol 9; Article 78

Sharf W, A Javaid, A Shoaib, IH Khan (2021). Induction of resistance in chili against Sclerotium rolfsii by plant growth promoting rhizobacteria and Anagallis arvensis. Egypt J Biol Pest Cont 31; Article 16

Sun Y, M Wang, Y Li, Z Gu, N Ling, Q Shen, S Guo (2017). Wilted cucumber plants infected by Fusarium oxysporum f. spp. cucumerinum do not suffer from water shortage. Ann Bot 120:427436

Tamang JP, PD Cotter, A Endo, NS Han, R Kort, SQ Liu, B Mayo, N Westerik, R Hutkins (2020). Fermented foods in a global age: East meets West. Compr Rev Food Sci Food Saf 19:184-217

Tan ZY, XD Xu, ET Wang, JL Gao, E Martinez-Romero, WX Chen (1997). Phylogenetic and genetic relationships of Mesorhizobium tianshanense and related rhizobia. Intl J Syst Evol Microbiol 47:874 879

Valenzuela AS, N ben Omar, H Abriouel, RL López, K Veljovic, MM Cañamero, MKL Topisirovic, A Galvez (2009). Virulence factors, antibiotic resistance, and bacteriocins in enterococci from artisan foods of animal origin. Food Cont 20:381-385

Varsha KK, S Priya, L Devendra, KM Nampoothiri (2014). Control of spoilage fungi by protective lactic acid bacteria displaying probiotic properties. Appl Biochem Biotechnol 172:3402-3413

Vijayaraghavan P, SGP Vincent (2013). A simple method for the detection of protease activity on agar plates using bromocresolgreen dye. $J$ Biochem Technol 4:628-630 
Wang L, M Dong, J Zheng, Q Song, W Yin, J Li, W Niu (2011). Relationship of biofilm formation and gelE gene expression in Enterococcus faecalis recovered from root canals in patients requiring endodontic retreatment. $J$ Endod 37:631-636

Xia Y, B Fei, J He, M Zhou, D Zhang, L Pan, S Li, Y Liang, L Wang, J Zhu, P Li, A Zheng (2017). Transcriptome analysis reveals the host selection fitness mechanisms of the Rhizoctonia solani AG1IA pathogen. Sci Rep 7; Article 10120
Zalipour M, BN Esfahani, SA Havaei (2019). Phenotypic and genotypic characterization of glycopeptide, aminoglycoside and macrolide resistance among clinical isolates of Enterococcus faecalis: A multicenter based study. BMC Res Notes 12; Article 292

Zandvakili N, M Zamani, M Motallebi, ZM Jahromi (2017). Cloning, overexpression and in vitro antifungal activity of Zea mays PR10 Protein. Iran J Biotechnol 15:42-49 